\title{
19
}

\section{WHERE WE TURN TO}

\section{Rethinking networks, urban space, and research methods}

\author{
Talja Blokland, Daniela Krüger, Robert Vief, \\ and Henrik Schultze
}

\section{To whom do we turn for support, and where?}

Activists and policymakers often assume that neighborhoods are significant for social support. Sociologists have a strong tradition of studying how social support develops and sustains in physical proximity of "neighborhoods." They study mobility as interfering with networks, neighborhoods, and an assumed warmth and strength of urban communities. Public concerns with individualization, lost community, and urban loneliness (Blokland 2017) reflect a re-assessment of personal ties in European cities in particular. Moreover, with the retreat of welfare states, Europeans have had to adjust to a rescaling of citizenship to the urban dimension (Blokland et al. 2015) and to state reorganization (Le Galès 2002).

Organizing non-state support was always standard in most cities worldwide (Swaan 1990). A comparative gesture (Robinson 2006) immediately highlights that beyond the state, getting things done may take different paths than fixed forms of social, cultural, and economic capital (Schilling, Blokland, and Simone 2019). Indeed, improvisations produce unplanned exchanges: urban ways of organizing resources are not often included, directly or routinely, in network-based sociology (Schilling, Blokland, and Simone 2019). Additionally, while cities have always attracted arrivals, globalization made routes longer. The network society (Castells 1996) refigures space in new ways (Knoblauch and Löw 2017). Translocal mobility has increased and distance no longer poses a significant hindrance to staying in touch. Thus, support cannot be simply assumed to be local.

\section{Social capital, ties, closeness}

Social capital, mostly defined as people's possibilities to get by or ahead (Briggs 1998) by virtue of embeddedness in social networks (Bourdieu 1986; Putnam 
2000; Portes 1998; Granovetter 1973), is central for measuring support. Scholars have mapped people's networks and investigated how neighborhood ties provide social capital (Völker and Flap 2007; Forrest and Kearns 2001; Middleton, Murie, and Groves 2005) in poverty concentration areas (Marques 2012; Wilson 2012; Rankin and Quane 2000; Osterling 2007) or mixed neighborhoods (Blokland and van Eijk 2010; Musterd and Andersson 2005; Galster 2007). Others asked whether moving from deprived neighborhoods produces new capital (Goering and Feins 2003; Curley 2010; Barwick 2016; Briggs, Popkin, and Goering 2010). Most studies share two ideas. First, they differentiate between strong, weak, and (sometimes) absent or invisible ties (Felder 2020). Second, they imply similar notions of how inequalities operate within those ties.

The usual differentiation between strong/weak/absent ties draws on Granovetter (1973). While absent ties—“"'nodding' relationship between people living on the same street" (Granovetter 1973, 1361) - have long been seen as a nonrelationship, social scientists have demonstrated that strong ties to close neighbors, kin, and friends help meeting needs and overcoming crises. In this context, scholars have not always clearly stated whether "closeness" is spatial or emotional, and what defines "emotional closeness." The strength of ties has been perceived as a "(probably linear) combination of the amount of time, the emotional intensity, the intimacy (mutual confiding), and the reciprocal services which characterize the tie" (Granovetter 1973, 1361; our italics). Therefore, studies typically measure closeness by frequency and reciprocity of help (e.g., Wellman and Wortley 1990; Kornienko et al. 2018) or by how many people respondents know, and how they perceive the tie's strength, then assuming an exchange of support (Marsden and Campbell 1984; McCarty 2002). Weak ties expand close-knit ("core") networks and provide information on important subjects such as job opportunities (Granovetter 1995). Scholars generally consider those ties to be unrelated to emotional, intimate support and instrumental, non-affective (Wegener 1991). Low interaction frequency becomes an indicator of weakness. Proximity, moreover, is generally measured by where network members live in relation to anchors (Mollenhorst 2015).

All this assumes that frequency creates intimacy, and that closeness means both disclosing secrecy and meeting often. While, practically, spatial closeness-living not far apart-influences interaction frequency even in digital times, especially for concrete forms of transferring things between people, emotional closeness does not depend on proximity. Lending sugar cannot be done over an app with far-away persons, but how far we (digitally) travel for emotionally supporting others may vary greatly. Closeness is curiously underdeveloped as a concept.

Another set of arguments regarding ties raises a similar issue. Sociologists acknowledge that the networked society provokes new kinds of relationships, but their research designs have not changed. A strong body of research has provided evidence that the internet boosts existing, face-to-face ties rather than new ones. Rainie and Wellman (2012) speak of a network revolution, characterized by a shift from group embeddedness (in families, work units, neighborhoods, or other groups) to networked individuals who knit together loosely connected or unrelated 
social circles. If digital technology has changed how people interact (Rainie and Wellman 2012), and online communication has expanded the reach, number, and velocity of ties (McEwen and Wellman 2013), did we also, maybe, change where and how we seek support? If how we interact has changed, has this also affected the closeness of ties? If group embeddedness has become less essential, is this true for all, or does spatiality affect ties in different ways, depending on agents' access to mobility?

Methodological discussions thus far have, firstly, often concentrated on whether people can recall names in name-generating questions, whether potential support is also activated, and whether weak ties are less commonly noted (see Brewer 2000). Few researchers methodologically discuss the role of space in distinctions between strong, weak, and absent ties.

Secondly, the division between strong/weak ties has been widely adopted in studies on urban inequalities. As poverty is so often studied in geographical pockets, a focus on local ties has developed since classics such as Stacks (1975) or Gans (1962). Studies of poor people start at where they live (e.g., Brisson and Usher 2007; Curley 2010), studies of middle-class people start with what they do, where they travel, and their elective belongingness (Andreotti, Le Galès, and MorenoFuentes 2014), and recent work on the super-rich focuses on enclaves (Atkinson 2019; Smithsimon 2010). Literature addressing the value of social mix for poor neighborhoods assumes that weak and strong ties benefit poor urbanites (Kleit 2008; Campbell and Lee 1992; Oliver 1988), suggesting that poor residents only live locally with networks of people residing in the same area, in contrast to affluent residents.

This research perspective prioritizes where we reside over where we spend time. Specific localities can become resource foci (Small 2009) — but this does not imply that network-ties exist close to each other or that all exchanges between residents "grow" into close network ties that name generators can catch. With changing ideas of what social networks are and how they operate, how we study them must also change (Wellman 1996). So, what happens when we do not follow the common ideas of weak/strong/absent ties and do not make "localness" a characteristic of a tie based on where network-members live? In other words: if being in each other's physical presence in a moment of need is an important yet overlooked element of how people organize resources (Small and Sukhu 2016), then where do people receive support?

\section{A focus on practices}

While other scholars have also challenged conventions of support and social and spatial proximity (Arbter 2016; Blokland and Nast 2014), Small (2017) formulated the strongest critique on the conceptualization of support in survey-based research. Small and his team conducted two interview rounds with first-year American graduate students. The students' graduate school was often located far away from former networks, thus creating new demands, systems, and sociability. Instead of 
tracing network ties and then their supportiveness, Small asked what challenges students faced and who supported them. The students often did not turn to strong ties and even kept troubles secret from them. They confided in people with whom they had weak ties: professionals, acquaintances, or strangers "who happened to be there." Small methodologically and empirically dismantled the assumptions that people have a fixed, durable set of people to whom they talk, and that kin and friends equate closeness and intimacy (also: Blokland 2019). It is not that strong ties do not matter, but rather that weak ties have been underestimated. Furthermore, how and why we avoid strong ties has been undertheorized. Small's interview partners give up secrecy (Simmel 1906) by revealing feelings like anxieties and fears. We intuitively tend to say that we share these feelings with closest friends and family. In practice, we do not always do so.

Small (2017) eloquently illustrated that, due to the fact that sociologists have measured (especially emotional) support rather non-reflexively from one research project to the next because variables "worked," we may have failed to see what happens in practice. From a different angle, we have argued in a similar direction (Blokland 2017; Blokland and Nast 2014) by showing that the division between strong/weak/absent ties neglects the contextual or spatial dimension of tie formation and maintenance. Whereas Small (2017) shows that in whom we confide depends partly on who happens to be there, we argued that support must not per definition come from strong or even weak ties. Instead, urban sociologists should pay special attention to absent ties. Neighborhood use patterns or running into the same people locally does not automatically result in fixed sets of ties that show up in network surveys, but can establish public familiarity (Blokland and Nast 2014, 1146). While moving with ease in such zones, we can engage casually with people who do not fit into categories of weak/strong ties (Blokland and Nast 2014, 1146). Yet, casual encounters may result in support and information. The extent to which they do so is not known: how sociologists study support has not included absent ties extensively (exception: Arbter 2016). Could public familiarity facilitate resourceful exchanges? Do only resources resulting from embeddedness in social networks constitute social capital, or can access to resources be acquired, maintained, or situationally negotiated more fleetingly (see Blokland et al. 2016)?

Part of the problem is confusion about the role of networks in social capital definitions - an overall connectivity of individuals, a web of affiliations (Simmel 1955) — with their meaning in survey measurements - names egos give. An indepth understanding of work with social capital requires understanding it as more than bonds/bridges. We may want to move away from a preoccupation with ties to one with practices (Blokland and Nast 2014; Blokland et al. 2016).

When we map people's networks and then measure their actual/potential support, we assume that we only get help from people we know, that ties must exist before being activated, and that gifts follow from ties. Starting with practices opens new perspectives. A gift may initiate a tie (Mauss 2002). Confiding can start a relationship, so that a person does not appear on a strong ties list when researchers ask their questions. Confiding in people we do not know well may have low risks of 
sanctions or debts. Seeking support in crises with close ties assumes shared norms. For some LGBTQ people coming out, religious people leaving their faith, seeking support with family and friends may not be an option. Less emotional labor may be involved when confiding in non-close ties: we do not have to think as much about what meaning personal concerns carry for others. If sociologists rely on (and reify) categories like friends, family, or neighbors and assume social qualities (e.g., intimacy, proximity, availability), we may forget that ties change and are never fixed (Blokland 2017, 65; Mollenhorst, Volker, and Flap 2014). Thus, we direct attention to potential productivity of interactions outside personal networks.

For this purpose, like Small (2017), we must incorporate contexts. The context of Small's students, however, was particular: they had institutionalized meeting moments. Elsewhere, Small (2009) also strongly argued that organizations may provide support. However, not all organizations do so equally: organizations with a high degree of institutionalized interactions like courts or emergency departments may do so differently than those with low routines, such as cafes, bars, clubs (Oldenburg and Brissett 1982), or bus stops (Desmond 2012). As such, the spatiality of meeting moments matters and provides people with different opportunities for "meeting and mating" (Small and Adler 2019).

Studies with qualitative research designs have already made these points. Most network researchers work with quantitative data for good reason. To bridge this, we thus must construct context-based but not context-specific surveys. Rather than asking issue-based questions to inquire into social networks (examples: Petermann 2015; Pfenning and Schenk 2014; Fischer 1982; Wellman and Wortley 1990), we may ask people, first, about which challenges they have recently faced, then who supported them, and finally where they and their supporter physically were at the moment of interaction.

Moreover, a great deal of literature emphasizes in situ face-to-face conversation for support. But increasing mobility and technological change may refigure the networks' spatiality, as noted earlier. We agree that the spatial dimension "is not just an accidental aspect but a basic feature of sociality" (Knoblauch and Löw 2017 , 11) and, in order to be able to thoroughly analyze processes of refiguration in social support, quantitative studies of social networks need to acknowledge the importance of the spatial dimension in survey tools. We may recognize, more than is currently the case in research on support, the relevance of spatiality and materiality for unequal access to social support.

\section{Bringing practices to the quantitative study of social support}

Qualitative analyses of people's personal challenges could suggest that more open approaches are not quantifiable (or not comparable), or that surveys (by definition) do not allow for more reflexive measurements (Wyly 2011). We think they do and propose measuring personal networks in urban settings by inverting several common survey logics. While studies on place-based social capital and neighborhood effects studies address neighborhoods to measure social relations, 
we propose only using the residence of people as a starting point to follow their practices. It is common practice in survey research to pre-define what support means. Surveys typically inquire about events that supposedly matter most for respondents. Many of these surveys are inspired by Fischer (1982) and revise, extend, and modify individual items. In doing so, surveys construct a set of fixed, hypothetical events (see ISSP 2000, 11-12): "Who would be the person taking care of your apartment when you're not in town," "Who would you get help from if you had the flu," or "Who are you going to go to when you want to borrow some money?" Other typical questions cover social actions within defined timespans (Mollenhorst, Volker, and Flap 2014; Pfenning and Schenk 2014; Fischer 1982; Bernard et al. 1990; Bien, Marbach, and Neyer 1991; Marsden 1987): "Who did you invite for dinner at your apartment over the last three months?"

Most ego-centered network surveys focus on social exchanges (e.g., sociability, emotional trust or functional daily help), mixing questions about real and hypothetical social actions and meetings (Burt 1984). This raises four issues:

1) Hypothetical assessment ("Who would do XY for you?") has a cognitive bias (Small and Sukhu 2016) and does not mean that respondents would actually receive support if the scenario were to occur ("A/B/C did XY for me").

2) Some surveys ask about events and encounters without inquiring about support: contacts are measured, not what actually happens. For example, persons invited for dinner over the last few months may have accepted the invitations for various reasons. What happens over dinner depends on who else is there, what the occasion was, whether kids joined the dinner table, etcetera. Was the dinner a moment of support? Dinners can be gaining (discussing emotional problems over a good plate of food in a relaxed setting) or draining (the socially desirable invite of parents-in-law sparks old conflicts). All in all, the names of who came for dinner feed equally on the social capital indicator; yet they reveal little more than the fact that people ate together.

3) Surveys often pre-define communication modes, reproducing 1980s ideas of valuable support without considering digitalization. Is it always more important to talk to someone face-to-face when having dinner than texting on the subway? Are voice messages less resourceful than a pub chat? Does seeing each other matter for all support? And if not, for which scenarios?

4) Existing research makes assumptions on how respondents use space to get support. Survey questions mapping networks tend to require or imply spatial proximity of the alter/ego. They specifically construct encounters in households or nearby facilities (such as bars and restaurants). Such constructs may overlook new (digital) forms of where we turn to others.

In short, many survey-based studies of ego-centered networks assume that researchers know which scenarios matter most to people, in what spatial context, and through what communication mode. 
This contradicts, remarkably, studies on globalization and transnationalism. Analyses of life-style pluralization, mobility, individualization, and increasing lifestage development varieties (Beck and Beck-Gernsheim 2010; Bauman 2013; Giddens 2013; Brüderl 2004; Knoblauch and Löw 2017) suggest that it is increasingly less accurate to assume a priori what forms of support people may need (or are able to provide). Hence, we should follow Small's (2017) openness to support scenarios.

Figure 19.1 summarizes our alternative survey design. We asked participants in face-to-face interviews to tell us about challenges that then became provisional labels. We invited respondents to think of anything from long-term burdens to everyday challenges. ${ }^{1}$

Using the scenario labels, we allow respondents to define their support and where they were when receiving it. We do not assume that ego and alter have met in person, even knew each other previously, or had informal ties: we only seek to learn to whom people turned when facing a challenge. A geocoding tool then recorded where respondents and supporters were and hence the geography of their support. When aggregated, this data assesses the neighborhood relevance: not as a rather un-defined or administratively defined concept, but as a set of possible "hubs" where residents interact to develop and maintain forms of support. While shortcomings exist, ${ }^{2}$ this measurement answers the lack of attention to spatiality in network data. The data structure makes it possible to analyze whether social support is local or translocal. It allows us to see whether mobility and migration influence support sites. Finally, we can analyze whether sites where people meet for support form neighborhood hubs, and whether (if at all) neighborhood organizations serve as sites where resources are exchanged between persons.

\section{Concluding thoughts on how our approach addresses support networks differently}

Research on support networks so far has worked with certain assumptions that require rethinking of how we measure. Many studies reify the importance of "tie strength" and an understanding of ties that equates closeness with intimacy.

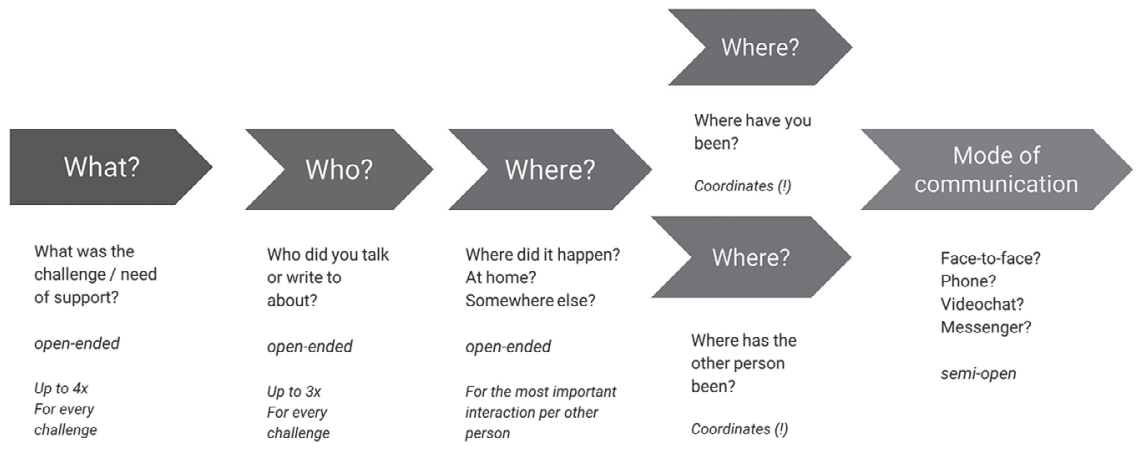

FIGURE 19.1 Alter-ego social support questions: alternative survey design 
This carries a Global North bias (Blokland 2019). We outlined an alternative approach.

Firstly, we suggest employing an open quantitative social network analysis to people's range of supportive interactions. Our tool moves from (strong/weak/ absent) ties (and their assumed qualities) to practices. Getting support does not always follow a clear intentionality of contacting certain ties. Our approach incorporates often overlooked fluid encounters and durable engagements.

Secondly, our tool provides new possibilities to map relations, spatial distances, and clusters. By means of spatial references, we can analyze social and spatial variability and inequality in support scenarios (for example, how space mediates support access for poor vs. affluent urbanites).

Thirdly, our tool acknowledges that there are different ways in which people communicate with each other. We should not assume that one form of communication is "right" and more substantially supportive. We can ask respondents to evaluate this for themselves. Gravity binds people to the ground (Gans 2002) but does not define what they mean to others. Mobility and digitalization may produce new networking routes, which we can now capture.

Finally, we reiterate the plea to turn network research upside down (Small 2017) with an appeal to integrate it into spatial contexts. Not only "who we turn to" but also where we turn to others matters for support.

\section{Acknowledgements}

This research has been funded by the Deutsche Forschungsgemeinschaft (DFG, German Research Foundation)—project number 290045248-SFB 1265.

\section{Notes}

1 "We are interested in where people get their support in the face of great, but also everyday challenges. Challenges are concerns, problems and obstacles that have to be overcome. This can concern work, family, school, health, emotional stress, but also completely different areas. What is or has been a challenge in your everyday life in the last 12 months?" We noted keywords of up to four challenges and used these scenarios in successive questions. People could name up to three alters with whom they talked about a challenge.

2 Like mapping fixed coordinates for scenarios where alter and ego moved (chat during a car ride) or enforcing choice of "most important" interaction when respondents had several important interactions in different contexts.

\section{References}

Andreotti, Alberta, Patrick Le Galès, and Francisco J. Moreno-Fuentes. 2014. Globalised Minds, Roots in the City. Chichester, UK: John Wiley \& Sons.

Arbter, Rebecca. 2016. "Social Ties and the Moral Orientation of Sharing." In Creating the Unequal City, edited by Talja Blokland, Carlotta Giustozzi, Daniela Krüger, and Hannah Schilling, 137-156. London: Routledge.

Atkinson, Rowland. 2019. "Necrotecture." International Journal of Urban and Regional Research 43 (1): 2-13. doi: 10.1111/1468-2427.12707. 
Barwick, Christine. 2016. Social Mobility and Neighbourhood Choice. New York: Taylor and Francis.

Bauman, Zygmunt. 2013. Liquid Modernity. Hoboken: Wiley.

Beck, Ulrich, and Elisabeth Beck-Gernsheim. 2010. Individualization. London: SAGE.

Bernard, H. Russell, Eugene C. Johnsen, Peter D. Killworth, Christopher McCarty, Gene A. Shelley, and Scott Robinson. 1990. "Comparing Four Different Methods for Measuring Personal Social Networks." Social Networks 12 (3): 179-215. doi: 10.1016/ 0378-8733(90)90005-T.

Bien, Walter, Jan Marbach, and Franz Neyer. 1991. "Using Egocentered Networks in Survey Research." Social Networks 13 (1): 75-90.

Blokland, Talja. 2017. Community as Urban Practice. Malden, MA: Polity Press.

Blokland, Talja. 2019. "Someone to Talk to, by Mario L. Small." Journal of Urban Affairs 41 (6): 881-883. doi: 10.1080/07352166.2018.1547548.

Blokland, Talja, Carlotta Giustozzi, Daniela Krüger, and Hannah Schilling, eds. 2016. Creating the Unequal City. London: Routledge.

Blokland, Talja, Christine Hentschel, Andrej Holm, Henrik Lebuhn, and Talia Margalit. 2015. "Urban Citizenship and Right to the City." International Journal of Urban and Regional Research 39 (4): 655-665. doi: 10.1111/1468-2427.12259.

Blokland, Talja, and Julia Nast. 2014. "From Public Familiarity to Comfort Zone.” International Journal of Urban and Regional Research 38 (4): 1142-1159.

Blokland, Talja, and Gwen van Eijk. 2010. "Do People Who Like Diversity Practice Diversity in Neighbourhood Life?" Journal of Ethnic and Migration Studies 36 (2): 313-332. doi: 10.1080/13691830903387436.

Bourdieu, Pierre. 1986. "The Forms of Capital." In Handbook of Theory and Research for the Sociology of Education, edited by John G. Richardson, 241-258. New York: Greenwood Pr.

Brewer, Devon D. 2000. "Forgetting in the Recall-based Elicitation of Personal and Social Networks." Social Networks 22 (1): 29-43. doi: 10.1016/S0378-8733(99)00017-9.

Briggs, Xavier de Souza. 1998. "Doing Democracy Up-Close.” Journal of Planning Education and Research 18 (1): 1-13. doi: 10.1177/0739456X9801800101.

Briggs, Xavier de Souza, Susan J. Popkin, and John M. Goering. 2010. Moving to Opportunity. New York: Oxford University Press.

Brisson, Daniel, and Charles L. Usher. 2007. "Conceptualizing and Measuring Bonding Social Capital in Low-Income Neighborhoods." Journal of Social Service Research 34 (1): 1-11. doi: 10.1300/J079v34n01_01.

Brüderl, Josef. 2004. "Die Pluralisierung partnerschaftlicher Lebensformen in Westdeutschland und Europa." Aus Politik und Zeitgeschichte (19): 3-10.

Burt, Ronald S. 1984. "Network Items and the General Social Survey." Social Networks 6 (4): 293-339. doi: 10.1016/0378-8733(84)90007-8.

Campbell, Karen E., and Barrett A. Lee. 1992. "Sources of Personal Neighbor Networks." Social Forces 70 (4): 1077-1100. doi: 10.1093/sf/70.4.1077.

Castells, Manuel. 1996. The Rise of the Network Society. Oxford: Blackwell.

Curley, Alexandra M. 2010. "Relocating the Poor." Journal of Urban Affairs 32 (1): 79-103. doi: 10.1111/j.1467-9906.2009.00475.x.

Desmond, Matthew. 2012. "Disposable Ties and the Urban Poor." American Journal of Sociology 117 (5): 1295-1335. doi: 10.1086/663574.

Felder, Maxime. 2020. "Strong, Weak and Invisible Ties." Sociology 54 (4): 675-692. doi: 10.1177/0038038519895938.

Fischer, Claude S. 1982. To Dwell Among Friends. Chicago: University of Chicago Press.

Forrest, Ray, and Ade Kearns. 2001. "Social Cohesion, Social Capital and the Neighbourhood.” Urban Studies 38 (12): 2125-2143. doi: 10.1080/00420980120087081. 
Galster, George. 2007. "Neighbourhood Social Mix as a Goal of Housing Policy." European Journal of Housing Policy 7 (1): 19-43. doi: 10.1080/14616710601132526.

Gans, Herbert J. 1962. The Urban Villagers. New York: Free Press.

Gans, Herbert J. 2002. "The Sociology of Space.” City \& Community 1 (4): 329-339. doi: 10.1111/1540-6040.00027.

Giddens, Anthony. 2013. Modernity and Self-Identity. Hoboken: Wiley.

Goering, John M., and Judith D. Feins, eds. 2003. Choosing a Better Life? Washington: Urban Institute Press.

Granovetter, Mark S. 1973. "The Strength of Weak Ties.” American Journal of Sociology 78 (6): 1360-1380.

Granovetter, Mark S. 1995. Getting a Job. Chicago: University of Chicago Press.

ISSP. 2000. "Social Relations and Support Systems (Social Networks II)." Accessed August 09, 2021. https://dbk.gesis.org/dbksearch/file.asp?file=ZA3680_bq.pdf.

Kleit, Rachel G. 2008. "Neighborhood Segregation, Personal Networks, and Access to Social Resources." In Segregation, edited by James H. Carr and Nandinee K. Kutty, 237260. London: Routledge.

Knoblauch, Hubert, and Martina Löw. 2017. "On the Spatial Re-Figuration of the Social World.” Sociologica 11 (2): 1-27. doi: 10.2383/88197.

Kornienko, Olga, Victor Agadjanian, Cecilia Menjívar, and Natalia Zotova. 2018. "Financial and Emotional Support in Close Personal Ties among Central Asian Migrant Women in Russia." Social Networks 53: 125-135.

Le Galès, Patrick. 2002. European Cities. New York: Oxford University Press.

Marques, Eduardo. 2012. Opportunities and Deprivation in the Urban South. Farnham: Ashgate.

Marsden, Peter V. 1987. "Core Discussion Networks of Americans." American Sociological Review 52 (1): 122-131. doi: 10.2307/2095397.

Marsden, Peter V., and Karen E. Campbell. 1984. "Measuring Tie Strength.” Social Forces 63 (2): 482-501. doi: 10.1093/sf/63.2.482.

Mauss, Marcel. 2002. The Gift. London: Routledge.

McCarty, Christopher. 2002. "Measuring Structure in Personal Networks." Journal of Social Structure 3 (1): 1-29.

McEwen, Rhonda, and Barry Wellman. 2013. "Relationships, Community, and Networked Individuals." In The Immersive Internet, edited by Robin Teigland and Dominic Power, 168-179. New York: Palgrave Macmillan. doi: 10.1007/978-1-137-28302-3_15.

Middleton, Alan, Alan Murie, and Rick Groves. 2005. "Social Capital and Neighbourhoods that Work.” Urban Studies 42 (10): 1711-1738. doi: 10.1080/00420980500231589.

Mollenhorst, Gerald. 2015. "Neighbour Relations in the Netherlands." Tijdschrift Voor Economische En Sociale Geografie 106 (1): 110-119. doi: 10.1111/tesg.12138.

Mollenhorst, Gerald, Beate Volker, and Henk Flap. 2014. "Changes in Personal Relationships." Social Networks 37: 65-80.

Musterd, Sako, and Roger Andersson. 2005. "Housing Mix, Social Mix, and Social Opportunities.” Urban Affairs Review 40 (6): 761-790. doi: 10.1177/1078087405276006.

Oldenburg, Ramon, and Dennis Brissett. 1982. "The Third Place." Qualitative Sociology 5 (4): 265-284. doi: 10.1007/BF00986754.

Oliver, Melvin L. 1988. "The Urban Black Community as Network.” The Sociological Quarterly 29 (4): 623-645.

Osterling, Kathy L. 2007. "Social Capital and Neighborhood Poverty." Journal of Human Behavior in the Social Environment 16 (1-2): 123-147. doi: 10.1300/J137v16n01_09.

Petermann, Sören. 2015. Persönliches soziales Kapital in Stadtgesellschaften. Wiesbaden: Springer Fachmedien. 
Pfenning, Uwe, and Michael Schenk. 2014. "Namensgeneratoren für egozentrierte soziale Netzwerke." Accessed August 09, 2021. https://zis.gesis.org/pdfFiles/Dokumentation/ Pfenning\%20Namensgeneratoren\%20fuer\%20egozentrierte\%20Netzwerke.pdf.

Portes, Alejandro. 1998. "Social Capital." Annual Review of Sociology 24 (1): 1-24.

Putnam, Robert D. 2000. Bowling Alone. New York: Simon \& Schuster.

Rainie, Lee, and Barry Wellman. 2012. Networked. Cambridge, MA: MIT Press.

Rankin, Bruce H., and James M. Quane. 2000. "Neighborhood Poverty and the Social Isolation of Inner-City African American Families.” Social Forces 79 (1): 139-164. doi: $10.2307 / 2675567$.

Robinson, Jennifer. 2006. Ordinary Cities. London: Routledge.

Schilling, Hannah, Talja Blokland, and AbdouMaliq Simone. 2019. "Working Precarity." The Sociological Review 67 (6): 1333-1349. doi: 10.1177/0038026119858209.

Simmel, Georg. 1906. "The Sociology of Secrecy and of Secret Societies." American Journal of Sociology 11 (4): 441-498. www.jstor.org/stable/2762562.

Simmel, Georg. 1955. Conflict and the Web of Group-Affiliations. New York: Free Press.

Small, Mario L. 2009. Unanticipated Gains. New York: Oxford University Press.

Small, Mario L. 2017. Someone to Talk to. New York: Oxford University Press.

Small, Mario L., and Laura Adler. 2019. "The Role of Space in the Formation of Social Ties." Annual Review of Sociology 45 (1): 111-132.

Small, Mario L., and Christopher Sukhu. 2016. "Because they Were There." Social Networks 47: 73-84.

Smithsimon, Gregory. 2010. "Inside the Empire." Urban Studies 47 (4): 699-724. doi: 10.1177/0042098009351940.

Stack, Carol B. 1975. All Our Kin. New York: Harper \& Row.

Swaan, Abram d. 1990. In Care of the State. Cambridge: Polity Press.

Völker, Beate, and Henk Flap. 2007. "Sixteen Million Neighbors." Urban Affairs Review 43 (2): 256-284. doi: 10.1177/1078087407302001.

Wegener, Bernd. 1991. “Job Mobility and Social Ties.” American Sociological Review 56 (1): 60-71. doi: 10.2307/2095673.

Wellman, Barry. 1996. “Are Personal Communities Local?” Social Networks 18 (4): 347-354. doi: 10.1016/0378-8733(95)00282-0.

Wellman, Barry, and Scot Wortley. 1990. "Different Strokes from Different Folks." American Journal of Sociology 96 (3): 558-588. doi: 10.1086/229572.

Wilson, William J. 2012. The Truly Disadvantaged. Chicago: The University of Chicago Press.

Wyly, Elvin K. 2011. "Positively Radical." International Journal of Urban and Regional Research 36 (3): 889-912. doi: 10.1111/j.1468-2427.2011.01047.x. 